INFLAMMATORY BOWEL DISEASE

\title{
Gut-associated bacterial microbiota in paediatric patients with inflammatory bowel disease
}

\author{
M P Conte, S Schippa, I Zamboni, M Penta, F Chiarini, L Seganti, J Osborn, \\ P Falconieri, O Borrelli, S Cucchiara
}

See end of article for authors' affiliations

\section{................... \\ Correspondence to:} S Cucchiara, Paediatric

Gastroenterology Unit, University of Rome La

Sapienza, Viale Regina Elena 324, Rome 00161 Italy;

salvatore.cucchiara@

uniromal.it

Revised 17 March 2006

Accepted 5 April 2006

Published Online First

28 April 2006

Background: Clinical and experimental observations in animal models indicate that intestinal commensal bacteria are involved in the initiation and amplification of inflammatory bowel disease (IBD). No paediatric reports are available on intestinal endogenous microflora in IBD.

Aims: To investigate and characterise the predominant composition of the mucosa-associated intestinal microflora in colonoscopic biopsy specimens of paediatric patients with newly diagnosed IBD.

Methods: Mucosa-associated bacteria were quantified and isolated from biopsy specimens of the ileum, caecum and rectum obtained at colonoscopy in 12 patients with Crohn's disease, 7 with ulcerative colitis, 6 with indeterminate colitis, 10 with lymphonodular hyperplasia of the distal ileum and in 7 controls. Isolation and characterisation were carried out by conventional culture techniques for aerobic and facultative-anaerobic microorganisms, and molecular analysis (16S rRNA-based amplification and realtime polymerase chain reaction assays) for the detection of anaerobic bacterial groups or species.

Results: A higher number of mucosa-associated aerobic and facultative-anaerobic bacteria were found in biopsy specimens of children with IBD than in controls. An overall decrease in some bacterial species or groups belonging to the normal anaerobic intestinal flora was suggested by molecular approaches; in particular, occurrence of Bacteroides vulgatus was low in Crohn's disease, ulcerative colitis and indeterminate colitis specimens.

Conclusion: This is the first paediatric report investigating the intestinal mucosa-associated microflora in patients of the IBD spectrum. These results, although limited by the sample size, allow a better understanding of changes in mucosa-associated bacterial flora in these patients, showing either a predominance of some potentially harmful bacterial groups or a decrease in beneficial bacterial species. These data underline the central role of mucosa-adherent bacteria in IBD.

$\mathrm{T}$ he gastrointestinal microbiota is usually described as a postnatally acquired organ, including a large variety of bacteria, the composition and activity of which can affect both systemic and intestinal physiology. ${ }^{1}$ Major functions of the intestinal microbiota include metabolic activities leading to saving of energy and absorbable nutrients, trophic effects on the intestinal epithelia, promotion of gut maturation and integrity, maintenance of intestinal immune homeostasis and defence against pathogenic bacteria. ${ }^{2}$ Modern microbiological analyses have documented that this complex microbial community varies in composition along the length of the gut (with an increased gradient from the stomach to the colon) and includes both rapidly transiting and relatively persisting organisms. ${ }^{1-3}$

The relationship between the immune system and the commensal flora is precarious, and its change may result in an inflammatory disease of the gut. In inflammatory bowel disease (IBD), an inappropriate response towards resident luminal bacteria induces devastating consequences if not promptly restrained. ${ }^{4}{ }^{5}$ However, the pathogenesis of IBD is a complex interplay among different interacting elements, such as host susceptibility, which is partly genetically determined, mucosal immunity and the intestinal milieu. ${ }^{6}$ Experimental evidence indicates that the loss of tolerance to commensal bacteria can be underlined by different factors, such as defects in regulatory $\mathrm{T}$ cell function, excessive stimulation of mucosal dendritic cells and changes in the receptorial pattern. ${ }^{7-9}$ Recent studies on the critical constituents in the innate immune response, such as pattern recognition receptors (ie, toll-like receptors and non-obese diabetic isoforms) also suggest that indigenous commensal microflora may contribute to intestinal inflammation in genetically susceptible hosts. ${ }^{3} 1011$

Indeed, to date, no specific bacterial agents have been identified as potential factors triggering intestinal inflammation, although the involvement of pathogenic bacteria cannot be excluded. Many studies have shown that bacterial flora differ between patients with IBD and healthy people. ${ }^{3561213}$ Patients with IBD have higher amounts of bacteria attached to their intestinal epithelial surface, even in the non-inflamed mucosa, than healthy controls. ${ }^{12}{ }^{14}{ }^{15}$ Swidsinski et al ${ }^{12}$ have shown that bacteria are from diverse genera and some of them, especially Bacteroides spp, were identified in the epithelial layer, in some instances intracellularly. Indeed, the role of Bacteroides spp in IBD is still unclear: these anaerobic bacteria have been shown to exhibit proinflammatory properties in several IBD animal models, but a protective role and even a decrease in the relative proportion of the phylogenetic group ${ }^{13}$ have been postulated in other studies. ${ }^{16}{ }^{17}$ Moreover, distinct adherent or invasive strains of Escherichia coli have been identified in the ileal mucosa of patients with Crohn's disease ${ }^{18}$ and the involvement of a new potentially pathogenic group of adherent invasive $E$ coli has been suggested. ${ }^{19-21}$ Recently, a breakdown in the balance between putative species of "protective" versus "harmful" intestinal bacteria, a concept referred to as "dysbiosis", has been postulated. ${ }^{22}$

Abbreviations: ATCC, American Type Culture Collection; cfu, colony forming units; IBD, inflammatory bowel disease; $\mathrm{LNH}$, lymphonodular hyperplasia; PCR, polymerase chain reaction 
However, although in the past decade data have been generated from in vitro studies, animal models and clinical trials on adult populations, the precise role of intestinal bacteria in IBD remains to be clarified. We investigated the predominant bacterial composition of the mucosa-associated intestinal microflora in colonoscopic biopsy specimens from the ileum, caecum and rectum in paediatric patients with a recent diagnosis of IBD (Crohn's disease, ulcerative colitis and indeterminate colitis) and in patients with lymphonodular hyperplasia (LNH) in the terminal ileum. ${ }^{23} \mathrm{~A}$ predominant or exclusive pattern of LNH in the distal ileum is not uncommonly diagnosed by paediatric gastroenterologists dealing with children investigated for symptoms and signs suggesting an IBD: whether it represents an early IBD is still disputed and is the object of studies. ${ }^{24}$ For our study, conventional bacterial isolation and culture techniques for aerobic and facultative-anaerobic bacteria, 16S rRNA-based amplification analysis for the detection of 14 anaerobic bacterial groups or species, and real-time polymerase chain reaction (PCR) for the quantitative determination of Bacteroides vulgatus have been used.

\section{PATIENTS AND METHODS Patients}

In all, 42 patients (age range 2-16 years) referred to the Paediatric Gastroenterology Unit, University of Rome "La Sapienza", Rome, Italy, for suspected IBD were studied: active Crohn's disease was diagnosed in 12, active ulcerative colitis in 7, indeterminate colitis in 6 and a diagnosis of LNH of the terminal ileum in 10. The LNH group presented with recurrent abdominal symptoms and signs, suggesting an inflammatory condition of the gut. Seven patients with functional intestinal disorder and with normal results on colonoscopy and histology served as controls. In the patient groups, there was no strong evidence of a difference in age or disease duration. The median (range) ages were 14.0 (1217) years for the Crohn's disease group, 10.0 (8-13) years for the ulcerative colitis group, 10.6 (9-13) years for the indeterminate colitis group, $11.2(8-14)$ years for the LNH group and 12.7 (9-16) years for the controls; median (range) disease duration were: 6 (2-12) weeks for the Crohn's disease group, $8(3-12)$ weeks for the ulcerative colitis group, 7 (2-12) weeks for the indeterminate colitis group, 6 (310) weeks for the LNH group and 8 (4-16) weeks for the controls. All children with Crohn's disease showed an ileocolonic involvement, and all of them had a disease activity score in the moderate to severe range. All patients with ulcerative colitis had endoscopic evidence of pancolitis, also showing a "backwash ileitis", and in all of them the disease was classified as severe. In patients with indeterminate colitis, the caecum and the right colon were the most commonly affected sites. The diagnostic investigation was carried out according to widely agreed international protocols. Infectious and systemic diseases as well as structural abnormalities of the gastrointestinal tract were excluded in all patients. No patient had food allergy or malabsorption, and invasive organisms, parasites and ova were not found in the stools. Clostridium difficile or its toxins were not detected in the stool of patients included in the study. Children who had received antibiotics within 3 months as well as those who had received any corticosteroid within 4 weeks before the study were excluded. No patients had previous treatment with azathioprine/6-mercaptopurine, ciclosporin or other immunosuppressive agents at any time before the enrolment. Patients who had received sulfasalazine or mesalazine were eligible if the drugs had been taken within a stable regimen for $>4$ weeks before the beginning of the study. Patients who had received a colonic cleaning procedure at least 3 months before the study were not eligible. All patients underwent ileocolonoscopy after parental informed written consent. In all patients, the colonic cleaning procedure was carried out using the same oral polyethylene glycol solution. The solution was given through a nasogastric tube if patients were poorly compliant. Endoscopy was performed in all patients by the same endoscopist with a paediatric videocolonoscope (Pentax 3440FK, Hamburg, Germany) after conscious sedation with intravenous pethidine $(1-2 \mathrm{mg} / \mathrm{kg})$ and midazolam $(0.1 \mathrm{mg} /$ $\mathrm{kg}$ ). Mucosa of the distal ileum and caecum was inspected for the presence of changes, such as lymphoid nodular hyperplasia, disappearance of vascular pattern, areas of erythema and oedema, erosions, ulcerations (small, large or serpiginous), cobblestoning and inflammatory polyps. Mucosal biopsy specimens were taken during endoscopy only from the macroscopically involved sites and examined for the presence of inflammatory features, such as increased cellularity of the lamina propria, basal lymphoid aggregates, crypt distortion or atrophy, cryptitis or crypt abscesses, goblet-cell depletion, epithelial abnormalities and granuloma in the lamina propria.

Ulcerative colitis was diagnosed when at least three of the following findings were present:

- history of diarrhoea, or blood or mucus in the stools;

- evidence of continuous macroscopic inflammation extending from the rectum to the proximal regions of the caecum;

- histological features typical of ulcerative colitis;

- exclusion of Crohn's disease of the small bowel through radiology, endoscopy and histology.

Crohn's disease was diagnosed when at least three of the following findings were present:

- typical clinical features, such as weight loss, abdominal pain and diarrhoea;

- typical features of macroscopic inflammation, such as discontinuous and patchy lesions, segmental inflammation, aphtoid ulcers, serpiginous or large ulcerations, cobblestoning or strictures;

- evidence of strictures on $x$ rays at the level of the small bowel, evidence of segmental colitis or fistulae;

- histological evidence of deep focal or diffuse inflammatory infiltrate towards the lamina propria or epithelioid granuloma with giant cells.

Indeterminate colitis was diagnosed if there were no definite criteria for the diagnosis of Crohn's disease or ulcerative colitis despite clear macroscopic or microscopic evidence of IBD. $^{25}$ LNH was diagnosed by endoscopy if clusters of lymphoid nodules were observed in the terminal ileum and in colonic areas after filling the area to be inspected with air.

\section{Treatment of biopsy specimens}

Biopsy specimens, taken from the ileum, caecum and rectum of the patients, were analysed for pathological evaluation of the inspected mucosa as well as for bacteriological study. For the bacteriological study, specimens were immediately processed in the Microbiology Laboratory, Public Health Department, University of Rome "La Sapienza", Rome, Italy. Biopsy washing was carried out according to Swidsinski $e t$ al. ${ }^{12}$ Briefly, two biopsy samples (15 mg of each) were first washed in $500 \mu \mathrm{l}$ of physiological saline with $0.016 \%$ dithioerythritol to remove the mucus and then washed three times in $500 \mu \mathrm{l}$ of physiological saline by shaking for $30 \mathrm{~s}$ each time. After the fourth wash, the biopsy specimens were hypotonically lysed by vortexing for $30 \mathrm{~min}$ in $500 \mu \mathrm{l}$ distilled water to analyse mucosal aerobic and facultative-anaerobic 
bacteria, or were processed for DNA extraction for the molecular detection of anaerobic bacteria.

\section{Culture conditions for aerobic and facultative- anaerobic bacteria}

The cell debris left after hypotonic lysis $(100 \mu \mathrm{l})$ was plated in tenfold dilution steps onto elective and differential media (Oxoid, Wiesel, Germany). For the isolation, Columbia blood agar for total microorganisms, selective Columbia blood agar with colistin-nalidix acid supplement for Gram-positive microorganisms, MacConkey agar without supplements for Enterobacteriaceae, Enterococcus-selective bile-aesculin azide agar for Enterococcus spp, Schiemann Cefsulodin, Irgasan, Novobiocin medium for Yersinia spp, Skirrow selective medium for Campylobacter spp, Oxford agar for Listeria spp and Sabouraud medium for yeasts were used. Single colonies were chosen for further investigations. Biochemical identification was determined by api 32 ID, api NE, api Strep, api Staph (bio-Mérieux-Italia, Rome, Italy) according to the manufacturer's procedure.

\section{Bacterial strains}

The strains listed below were obtained from the American Type Culture Collection (ATCC) and used to evaluate the specificity of the PCR primer set: Bifidobacterium adolescentis ATTC 15703, Bifidobacterium longum ATTC 15707, Eubacterium biforme ATTC 27806, Fusobacterium prausnitzii ATTC 27766, Peptostreptococcus productus, ATTC 27340, Lactobacillus acidophilus ATCC 11975, Bacteroides fragilis ATTC 23745, Bacteroides thetaiotaomicron ATTC 29148, Bacteroides vulgatus ATTC 8482, Bacteroides distasonis ATTC 8503, Clostridium clostridiiforme ATCC 25537. Lactobacillus acidophilus was grown in lactobacilli de Man, Rogosa and Sharpe broth (Oxoid); all other microorganisms were cultured on anaerobe basal plates or broth (Oxoid) and incubated in an anaerobic chamber (in an atmosphere of $80 \%$ nitrogen, $10 \%$ carbon dioxide and $10 \%$ hydrogen) at $37^{\circ} \mathrm{C}$.

\section{DNA extraction}

After the fourth washing, the biopsy specimens were incubated with $180 \mu \mathrm{l}$ ATL buffer and $20 \mu \mathrm{l}$ proteinase $\mathrm{K}$ (Sigma-Aldrich, St Louis, Missouri, USA) at $55^{\circ} \mathrm{C}$ for $2 \mathrm{~h}$ and then with $20 \mu \mathrm{l}$ lysozyme for a further $2 \mathrm{~h}$ at $37^{\circ} \mathrm{C}$. DNA was extracted with the DNeasy Tissue Kit (Qiagen, Hilden, Germany) according to the manufacturer's instructions. DNA concentration was determined using an Eppendorf biophotometer at $260 \mathrm{~nm}$. In the amplification assays, $50 \mathrm{ng}$ of DNA were used.

\section{PCR amplification assays}

The suitability of DNA for analysis was checked by amplification of the $\beta$-globin gene sequence. Aliquots of each DNA sample (50 ng) were amplified with specific primers: forward primer, 5'-CAACTTCATCCACGTTCACC-3; reverse primer, 5'-GAAGAGCCAAGGACAGGTAC-3'. Amplification reactions were carried out in a 50- $\mu$ l volume containing $1 \times$ PCR buffer II (Applied Biosystems, Roche, California, USA), $3 \mathrm{mM}$ magnesium chloride, $200 \mu \mathrm{M}$ each deoxynucleoside triphosphate, 50 pmol each primer and $5 \mathrm{U} \mu / \mathrm{l}$ AmpliTaq Gold polymerase (Applied Biosystems). The PCR was carried out under the following conditions: 1 cycle of $95^{\circ} \mathrm{C}$ for $7 \mathrm{~min}, 35$ cycles of $94^{\circ} \mathrm{C}$ for $1 \mathrm{~min}, 55^{\circ} \mathrm{C}$ for $1 \mathrm{~min}$ and $72^{\circ} \mathrm{C}$ for $1 \mathrm{~min}$ and 1 cycle of $72^{\circ} \mathrm{C}$ for $7 \mathrm{~min}$.

The 16S rRNA-gene-targeted primers used for the detection of anaerobic bacterial species or groups were synthesised by M-Medical Genenco, according to the sequences already published by Wang et $a l^{26}$ and Matsuki et al ${ }^{27}$ (table 1). Amplification reactions were carried out in a 50 - $\mu$ l volume containing $1 \times$ PCR buffer II, $50 \mathrm{pmol}$ of each primer and
$5 \mathrm{U} / \mu \mathrm{l}$ of AmpliTaq Gold polymerase. The amplification programme for Prevotella spp, Bifidobacterium spp (that includes $B$ adolescentis, $B$ breve, $B$ catenulatum and $B$ longum), Clostridium coccoides group (that includes $C$ clostridiiforme, Ruminococcus gnavus and $C$ coccoides) and Bacteroides fragilis group (that includes $B$ caccae, $B$ fragilis, $B$ ovatus and $B$ thetaiotaomicron) was 1 cycle of $95^{\circ} \mathrm{C}$ for $7 \mathrm{~min}, 40$ cycles of $94^{\circ} \mathrm{C}$ for $20 \mathrm{~s}, 55^{\circ} \mathrm{C}$ or $50^{\circ} \mathrm{C}$ for $20 \mathrm{~s}, 72^{\circ} \mathrm{C}$ for $30 \mathrm{~s}$ and 1 cycle of $72^{\circ}$ for $5 \mathrm{~min}$. The PCR for Clostridium clostridiiforme, Bacteroides thetaiotaomicron, Bacteroides distasonis, Bacteroides vulgatus, Bifidobacterium adolescentis, Bifidobacterium longum, Eubacterium biforme, Fusobacterium prausnitzii, Lactobacillus acidophilus and Peptostreptococcus productus was carried out under the following conditions: 1 cycle of $95^{\circ} \mathrm{C}$ for $7 \mathrm{~min}, 35$ cycles of $94^{\circ} \mathrm{C}$ for $3 \mathrm{~s}, 55^{\circ} \mathrm{C}$ or $50^{\circ} \mathrm{C}$ for $10 \mathrm{~s}$, and $74^{\circ} \mathrm{C}$ for $35 \mathrm{~s}$, 1 cycle of $74^{\circ} \mathrm{C}$ for $2 \mathrm{~min}$ and $45^{\circ} \mathrm{C}$ for $2 \mathrm{~s}$. The amplification products were subjected to gel electrophoresis in $2 \%$ agarose.

\section{Real-time PCR assays}

The primers and probes for Bacteroides vulgatus were based on 16S rRNA gene sequences available from GenBank. The GenBank programme BLAST was used to ensure that the proposed primers were complementary with the target species but not with other species. The primers and probe were selected from these specific sequences with Primer Express software V.2.0, provided with the ABI Prism 7300 sequence detector, and were obtained from Applied Biosystems. For Bacteroides vulgatus, the forward primer sequence was 5'-CAGTTGAGGCAGGCGGAAT-3', the reverse primer sequence was 5'-CCTTCGCAATCGGAGTTCTT-3' and the sequence of the probe was $5^{\prime}$-CGTGGTGTAGCGG TGAAATGCTTAGATATCA-3'. The fluorescent reporter dye at the $5^{\prime}$ end of the probe was 6-carboxyfluorescein; the quencher at the 3' end was 6-carboxy- $\mathrm{N}, \mathrm{N}, \mathrm{N}$, $\mathrm{N}$-tetramethylrhodamine. The real-time PCR amplifications were carried out in $25 \mu \mathrm{l}$ reaction volumes containing $2 \times$ TaqMan Universal Master Mix (Applied Biosystems), each primer at a concentration of $300 \mathrm{nM}$, fluorescent-labelled probe at a concentration of $200 \mathrm{nM}$, and $4 \mu \mathrm{l}$ (50 ng) of DNA extracted from biopsy specimens. All reactions were performed in duplicate, and for amplification and detection, an ABI PRISM 7300 sequence detection system was used. The amplification parameters used were as follows: $50^{\circ} \mathrm{C}$ for $2 \mathrm{~min}$ and $95^{\circ} \mathrm{C}$ for $10 \mathrm{~min}$, followed by 40 cycles, each of which comprised $95^{\circ} \mathrm{C}$ for $15 \mathrm{~s}$ and $55^{\circ} \mathrm{C}$ for 1 min. Each run contained both negative and positive controls. Real-time data were analysed with Sequence Detection Systems software (Becton-Dickinson).

A reference curve for Bacteroides vulgatus ATCC 8482 was generated as follows: the bacteria were grown anaerobically in $10 \mathrm{ml}$ of anaerobe basal broth (Oxoid) at $37^{\circ} \mathrm{C}$ for $24 \mathrm{~h}$. These cultures were diluted with physiological saline until they reached a McFarland 0.5 standard, representing $10^{8}$ microorganisms $/ \mathrm{ml}$, as determined by plating $100 \mu \mathrm{l}$ of tenfold serial dilutions of these cultures onto anaerobe basal agar plates (Oxoid); these dilutions were used for DNA extraction with UltraClean (MO BIO Laboratories, Solana Beach, California, USA) according to the manufacturer's instructions. Starting from a DNA concentration of $50 \mathrm{ng}$, tenfold dilutions were prepared to obtain different cell concentrations (concentration range 0.005-50 $000 \mathrm{pg}$ ). The assay was run twice for each dilution, with $C_{t}$ values ranging between 12.8 and 33.6. Equivalent copy number and $\mathrm{C}_{\mathrm{t}}$ were automatically generated by the instrument for two replicate sets of controls. The reference curve was used to extrapolate the equivalent number of colony-forming units (cfu) of Bacteroidesvulgatus in the biopsy specimens. 
Table 1 Polymerase chain reaction primers used

\begin{tabular}{|c|c|c|c|c|}
\hline Target bacteria & Primer & Sequence $\left(5^{\prime} \rightarrow 3^{\prime}\right)$ & Product size (bp) & Reference \\
\hline Prevotella & $\begin{array}{l}\text { g-Prevo-F } \\
\text { g-Prevo-R }\end{array}$ & $\begin{array}{l}\text { CACRGTAAACGATGGATGCC } \\
\text { GGTCGGGTGCAGACC }\end{array}$ & $527-529$ & Matsuki et a $P^{7}$ \\
\hline Bifidobacterium spp & $\begin{array}{l}\text { g-Bifid-F } \\
\text { g-Bifid-R }\end{array}$ & $\begin{array}{l}\text { CTCCTGGAAACGGGTGG } \\
\text { GGTGTTCTTCCCGATATCTACA }\end{array}$ & $549-563$ & Matsuki et $a^{P^{7}}$ \\
\hline Clostridium coccoides group & $\begin{array}{l}\mathrm{g}-\mathrm{C} \operatorname{coc}-\mathrm{F} \\
\mathrm{g}-\mathrm{C} \operatorname{coc}-\mathrm{R}\end{array}$ & $\begin{array}{l}\text { AAATGACGGTACCTGACTAA } \\
\text { CITTGAGTTCATTCTTGCGAA }\end{array}$ & $438-441$ & Matsuki ef $a^{p^{7}}$ \\
\hline Clostridium clostridiiforme & $\begin{array}{l}\text { CC-1 } \\
\text { CC-2 }\end{array}$ & $\begin{array}{l}\text { CCGCATGGCAGTGTGTGAAA } \\
\text { CTGCTGATAGAGCTTACATA }\end{array}$ & 255 & Wang et apo \\
\hline Bacteroides fragilis group & $\begin{array}{l}\text { g-BfraF } \\
\text { g-BfraR }\end{array}$ & $\begin{array}{l}\text { ATAGCCTTTCGAAAGRAAGAT } \\
\text { CCAGTATCAACTGCAATTTIA }\end{array}$ & 501 & Matsuki et ap \\
\hline Bacteroides thetaiotaomicron & $\begin{array}{l}\text { BT-1 } \\
\text { BT-2 }\end{array}$ & $\begin{array}{l}\text { GGCAGCATTCAGTTIGCTTG } \\
\text { GGTACATACAAAATTCCACACGT }\end{array}$ & 423 & Wang et af ${ }^{p}$ \\
\hline Bacteroides vulgatus & $\begin{array}{l}\text { BV-1 } \\
\text { BV-2 }\end{array}$ & $\begin{array}{l}\text { GCATCATGAGTCCGCATGTTC } \\
\text { TCCATACCCGACTTITATCCTT }\end{array}$ & 287 & Wang et $a^{p o}$ \\
\hline Bacteroides distasonis & $\begin{array}{l}\text { BD-1 } \\
\text { BD-2 }\end{array}$ & $\begin{array}{l}\text { GTCGGACTAATACCGCATGAA } \\
\text { TIACGATCCATAGAACCTTCAT }\end{array}$ & 273 & Wang et af ${ }^{p}$ \\
\hline Bifidobacterium adolescentis & $\begin{array}{l}\text { BIA-1 } \\
\text { BIA-2 }\end{array}$ & $\begin{array}{l}\text { GGAAAGATTCTATCGGTATGG } \\
\text { CTCCCAGTCAAAAGCGGTT }\end{array}$ & 244 & Wang et $a^{p 6}$ \\
\hline Bifidobacterium longum & $\begin{array}{l}\text { BIL-1 } \\
\text { BIL-2 }\end{array}$ & $\begin{array}{l}\text { GTCCCGACGGTCGTAGAG } \\
\text { GTGAGTTCCCGGCATAATCC }\end{array}$ & 153 & Wang et $a^{p 6}$ \\
\hline Eubacterium biforme & $\begin{array}{l}\mathrm{EBI}-1 \\
\mathrm{EBI}-2\end{array}$ & $\begin{array}{l}\text { GCTAAGGCCATGAACATGGA } \\
\text { GCCGTCCTCTCTGTCTC }\end{array}$ & 46 & Wang et a ${ }^{p o}$ \\
\hline Fusobacterium prausnitzii & $\begin{array}{l}\text { FPR-1 } \\
\text { FPR-2 }\end{array}$ & $\begin{array}{l}\text { AGATGGCCTCGCGTCCGA } \\
\text { CCGAAGACCTTCTTCCTCC }\end{array}$ & 199 & Wang et $a^{p o}$ \\
\hline Peptostreptococcus productus & $\begin{array}{l}\text { PSP-1 } \\
\text { PSP-2 }\end{array}$ & $\begin{array}{l}\text { AACTCCGGTGGTATCAGATG } \\
\text { GGGGCTTCTGAGTCAGGTA }\end{array}$ & 268 & Wang et $a^{26}$ \\
\hline Lactobacillus acidophilus & $\begin{array}{l}\text { LAA-1 } \\
\text { LAA-2 }\end{array}$ & $\begin{array}{l}\text { CATCCAGTGCAAACCTAAGAG } \\
\text { GATCCGCTTGCCTTCGCA }\end{array}$ & 286 & Wang et $a^{p o}$ \\
\hline
\end{tabular}

\section{Statistical analysis}

All significance tests carried out were non-parametric. For comparisons between two groups the Mann-Whitney U test was used and to compare more than two groups the Kruskall-Wallace method, analogous to one-way analysis of variance, was used. The levels of significance reported are not adjusted to take account of multiple comparisons. As these are multiple comparisons, $p$ values $<1 \%$ were considered significant to imply strong evidence of a difference.

\section{RESULTS}

Mucosa-associated aerobic and facultative-anaerobic bacterial concentrations in different gut locations

The concentration of mucosa-associated bacteria after the fourth wash and hypotonic lysis from ileum, caecum and rectum biopsy specimens of paediatric patients with IBD and LNH was compared with that of controls (table 2). As shown in table 2, in the ileum, total aerobe and facultative-anaerobe counts, as well as total Gram-negative bacterial counts, were significantly higher in patients with Crohn's disease, ulcerative colitis and indeterminate colitis than in controls. Although an increased number of Gram-positive bacteria were also detected in mucosal biopsy specimens of patients with IBD, the difference was not significantly different from controls. In the ileal mucosa of the patients with LNH, the whole bacterial concentration and that of Gram-negative and Gram-positive bacteria were increased. In table 2, in both LNH and the other IBD subgroups, a generalised increase in total mucosa-associated bacteria was observed in the other locations analysed in the gut (caecum and rectum). The trend of bacterial concentration in the different gut locations showed a higher number of bacterial counts in the ileum and rectum, coupled with a lower colonisation in the caecum, whereas in controls the bacterial colonisation was lower in all the segments examined.

Figure 1 shows the percentage of patients with different concentration ranges of ileal mucosal bacteria (undetectable$<1000,1000-<10000,10000-<100000$ and $>100000 \mathrm{cfu} /$ $\mathrm{ml})$. Up to $90 \%$ of controls and $65 \%$ of patients with LNH showed concentrations of bacteria $<1000 \mathrm{cfu} / \mathrm{ml}$, whereas higher bacterial concentrations were prevalent in biopsy specimens of patients with IBD, reaching values $>100000 \mathrm{cfu} / \mathrm{ml}$ in $22 \%, 33 \%$ and $40 \%$ of patients with Crohn's disease, ulcerative colitis and indeterminate colitis, respectively.

\section{Distribution of bacterial isolates from aerobic and facultative-anaerobic culture of ileum mucosa}

Identification of the bacteria from ileal mucosa in all patient groups showed that 54 of 104 (52\%) cultured isolates were Gram negative, whereas the remaining were Gram positive. Among Gram-negative organisms, only bacteria belonging to the Enterobacteriaceae family were found: 38 of 54 (74\%) were identified as E coli, 13 (24\%) as Klebsiella spp and $3(6 \%)$ as Proteus spp, whereas in control samples $E$ coli was the only Gram-negative species found. All of these species were 
Table 2 Median concentrations (range; $\times 103 \mathrm{cfu} / \mathrm{ml}$ ) of aerobic and facultative anaerobic bacteria detected after lysis of biopsy specimens

\begin{tabular}{|c|c|c|c|c|c|c|}
\hline & Controls, $n=7$ & $C D, n=12$ & UC, $n=7$ & IC, $n=6$ & LNH, $n=10$ & $\mathrm{~K}-\mathrm{W}^{*}$ \\
\hline \multicolumn{7}{|l|}{ lleum } \\
\hline \multirow{2}{*}{$\begin{array}{l}\text { Total aerobes and } \\
\text { facultative anaerobes }\end{array}$} & $0(0-2.4)$ & $147(3.31-1100)$ & $150(11.6-400)$ & $201(40.6-780)$ & $7.9(0.007-480)$ & $p=0.001$ \\
\hline & & $p=0.005$ & $p=0.005$ & $p=0.005$ & $p=0.01$ & \\
\hline $\begin{array}{l}\text { Total Gram-negative } \\
\text { bacteria† }\end{array}$ & $0(0-0.26)$ & $147(0.8-830)$ & $150(10.6-350)$ & $120(0-400)$ & $9.8(0-480)$ & $p=0.046$ \\
\hline \multirow{3}{*}{$\begin{array}{l}\text { Total Gram-positive } \\
\text { bacteriał }\end{array}$} & $0(0-2.35)$ & $\begin{array}{l}p=0.005 \\
0.77(0-55)\end{array}$ & $\begin{array}{l}p=0.005 \\
7.2(0-150)\end{array}$ & $\begin{array}{l}p=0.01 \\
50.9(0.4-580)\end{array}$ & $\begin{array}{l}p=0.01 \\
0.35(0-20)\end{array}$ & $p=0.039$ \\
\hline & & $p=0.18$ & $p=0.05$ & $p=0.01$ & $p=0.49$ & \\
\hline & Controls, $n=4$ & $C D, n=11$ & UC, $n=6$ & IC, $n=4$ & LNH, $n=5$ & \\
\hline \multicolumn{7}{|l|}{ Caecum } \\
\hline $\begin{array}{l}\text { Total aerobes and } \\
\text { facultative anaerobes }\end{array}$ & $0.88(0-50)$ & $54(2.09-660.49)$ & $64(10.59-360.36)$ & $350(10.15-518)$ & $16(0.16-100)$ & $p=0.056$ \\
\hline \multirow{2}{*}{$\begin{array}{l}\text { Total Gram-negative } \\
\text { bacteria† }\end{array}$} & $0.08(0-50)$ & $\begin{array}{l}p=0.02 \\
53(0.26-660)\end{array}$ & $\begin{array}{l}p=0.07 \\
57(1-360)\end{array}$ & $\begin{array}{l}p=0.06 \\
64(10-300)\end{array}$ & $\begin{array}{l}p=0.29 \\
0.16(0-100)\end{array}$ & $p=0.074$ \\
\hline & $0(0-1.6)$ & $\begin{array}{l}p=0.02 \\
0.5(0-83)\end{array}$ & $\begin{array}{l}p=0.07 \\
2.33(0.16-80.6)\end{array}$ & $\begin{array}{l}p=0.11 \\
150(0.15-490)\end{array}$ & $\begin{array}{l}\mathbf{p}=\mathbf{0 . 7 3} \\
0.3(0-100)\end{array}$ & $\mathrm{p}=0.347$ \\
\hline \multirow{2}{*}{$\begin{array}{l}\text { Total Gram-positive } \\
\text { bacteriał }\end{array}$} & & $p=0.17$ & $p=0.07$ & $p=0.06$ & $p=0.4$ & \\
\hline & Controls, $n=4$ & $C D, n=8$ & UC, $n=6$ & IC, $n=4$ & LNH, $n=5$ & \\
\hline \multicolumn{7}{|l|}{ Rectum } \\
\hline $\begin{array}{l}\text { Total aerobes and } \\
\text { facultative anaerobes }\end{array}$ & $4.21(0.97-50)$ & 186.05 (100-739) & $28.3(10.76-138.7)$ & $460(268.6-1200)$ & $60(0.92-510)$ & $p=0.006$ \\
\hline $\begin{array}{l}\text { Total Gram-negative } \\
\text { bacteria† }\end{array}$ & $1.4(0-30)$ & $\begin{array}{l}\mathbf{p}<0.005 \\
164.5(60-650)\end{array}$ & $\begin{array}{l}p=0.11 \\
28(10.6-109)\end{array}$ & $\begin{array}{l}p=0.03 \\
115.5(20-400)\end{array}$ & $\begin{array}{l}p=0.29 \\
2.4(0-500)\end{array}$ & $p=0.20$ \\
\hline \multirow{2}{*}{$\begin{array}{l}\text { Total Gram-positive } \\
\text { bacteriał }\end{array}$} & $2.81(0.97-20)$ & $\begin{array}{l}p=0.00 \\
44.55(0-90)\end{array}$ & $\begin{array}{l}p=0.07 \\
0.3(0-473)\end{array}$ & $\begin{array}{l}p=0.11 \\
312.8(120-1000)\end{array}$ & $\begin{array}{l}p=0.90 \\
2.32(0-100)\end{array}$ & $p=0.001$ \\
\hline & & $p=0.21$ & $p=0.48$ & $p=0.03$ & $p=0.90$ & \\
\hline
\end{tabular}

$\mathrm{CD}$, Crohn's disease; cfu, colony forming units; IC, indeterminate colitis; K-W, Kruskal-Wallis; LNH, lymphonodular hyperplasia, UC, ulcerative colitis. *p Values obtained from the Kruskal-Wallis test for the five groups.

tData refer to Enterobacteriaceae, which were the predominant bacteria found.

†Data refer to Staphylococcus and Streptococcus spp, which were the predominant bacteria found.

Bold values as compared with controls using the Mann-Whitney $U$ test.

Owing to the multiple comparisons, only $p \leqslant 0.01$ should be interpreted as strong evidence of a difference.

represented in mucosal samples of patients with Crohn's disease and in an average of almost two in the other pathological samples examined. The Gram-positive population

$$
\begin{array}{|l|l|}
\square 0-<1000 \mathrm{cfu} / \mathrm{ml} & \square 10000-<100000 \mathrm{cfu} / \mathrm{ml} \\
\square 1000-<10000 \mathrm{cfu} / \mathrm{ml} & \square>100000 \mathrm{cfu} / \mathrm{ml}
\end{array}
$$

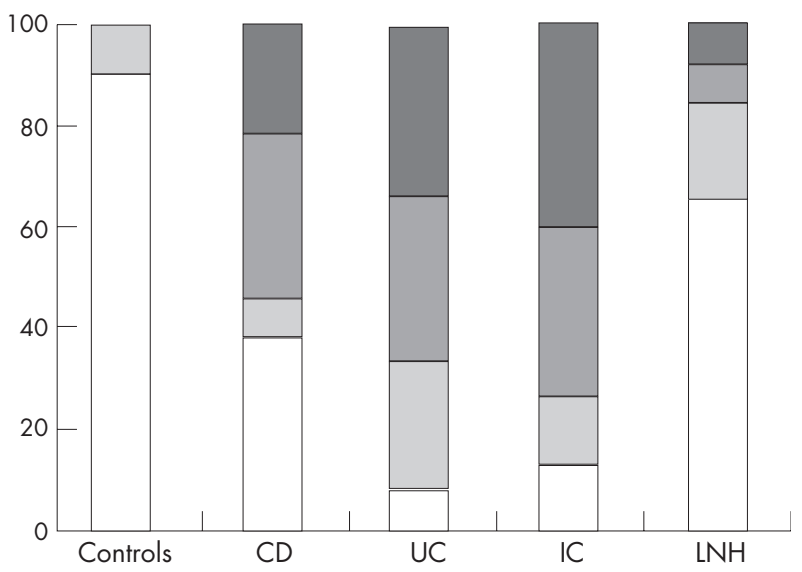

Figure 1 Percentage of patients with different concentrations of total aerobic and facultative-anaerobic mucosal bacteria. CD, Crohn's disease; cfu, colony forming units; IC, indeterminate colitis; LNH, lymphonodular hyperplasia, UC, ulcerative colitis. was represented by Streptococcus spp, Enterococcus spp and Staphylococcus spp, accounting for 18 (36\%), 27 (54\%) and 10 $(20 \%)$ of 50 Gram-positive isolates, respectively.

Table 3 gives the occurrence of aerobic and facultativeanaerobic Gram-negative and Gram-positive species in ileal mucosa biopsy specimens, reported as number and percentage of isolates found in relation to the total Gram-negative or Gram-positive isolates detected in each patient group. Data analysis showed a generalised similar distribution of bacterial species isolated among all patient groups, with the species most markedly represented in specimens from ileum belonging to Escherichia and Enterococcus genera. Listeria, Yersinia, Campylobacter and yeasts were never cultured.

When the occurrence of bacterial species in each patient group was analysed, E coli was detected in 9 of the $12(75 \%)$ patients with Crohn's disease, in all $(100 \%)$ patients with ulcerative colitis, in 3 of the $6(50 \%)$ patients with indeterminate colitis, in 8 of the $11(72 \%)$ patients with LNH and in 2 of the 8 (25\%) controls. Enterococcus spp was detected in 6 of the $12(50 \%)$ patients with Crohn's disease, in 5 of the $7(71 \%)$ patients with ulcerative colitis, in 4 of the $6(67 \%)$ patients with indeterminate colitis, in 3 of the 11 (23\%) patients with LNH and in 3 of the $8(37 \%)$ controls. Klebsiella spp were found only in biopsy specimens from patients with IBD and, in particular, its detection was markedly increased in patients with indeterminate colitis (83\%).

A similar trend was found for the occurrence of Gramnegative and Gram-positive species from cultures of biopsy 
Table 3 Distribution of bacterial isolates from aerobic and facultative-anaerobic culture of ileal mucosal samples

\begin{tabular}{|c|c|c|c|c|c|c|c|c|}
\hline & $\begin{array}{l}\text { Total Gram } \\
\text { negative }\end{array}$ & $\begin{array}{l}\text { Total Gram } \\
\text { positive }\end{array}$ & E coli & Klebsiella spp & Proteus spp & Streptococcus spp & Enterococcus spp & Staphylococcus spp \\
\hline & $n(\%)$ & $n(\%)$ & $n(\%)$ & $n \%$ & $n(\%)$ & $n$ (\%) & $n(\%)$ & $n(\%)$ \\
\hline Controls & $3(30.0)$ & $7(70.0)$ & $3(100)$ & $0(0.0)$ & $0(0.0)$ & $2(28.5)$ & $4(57.0)$ & 1 (14.2) \\
\hline$C D$ & 18 (51.4) & $12(48.6)$ & $12(66.7)$ & $3(16.7)$ & $3(16.7)$ & $5(29.4)$ & $8(47.1)$ & $4(23.5)$ \\
\hline UC & $12(50.0)$ & $12(50.0)$ & $10(83.3)$ & $2(16.6)$ & $0(0.0)$ & $4(33.3)$ & $8(66.6)$ & $0(0.0)$ \\
\hline IC & $7(46.6)$ & $8(53.3)$ & $3(42.8)$ & $4(57.1)$ & $0(0.0)$ & $2(25.0)$ & $4(50.0)$ & $2(25.5)$ \\
\hline LNH & $14(44.0)$ & $11(56.0)$ & 20 (71.4) & $4(28.6)$ & $0(0.0)$ & $5(45.4)$ & $3(27.3)$ & $3(27.3)$ \\
\hline
\end{tabular}

$C D$, Crohn's disease; IC, indeterminate colitis; $L N H$, lymphonodular hyperplasia; $n$, number of bacterial isolates; UC, ulcerative colitis; \%, percentage of strains isolated in ileum mucosa biopsy specimens calculated as number of isolates found with respect to total Gram-negative or Gram-positive isolates detected in each group.

specimens derived from the caecum and rectum (data not shown).

\section{Percentage of patients with positive PCR for anaerobic bacterial groups or species}

The biodiversity of mucosa-associated anaerobic flora from ileum, caecum and rectum specimens was assessed by PCR. The choice of the anaerobic bacterial groups and species was based on previous reports that treated the relative frequency of bacterial species found in the human intestinal tract ${ }^{28}$ associated with the mucosa of healthy people and patients with IBD, ${ }^{29}$ and detectable in the normal faecal flora. ${ }^{30}$ Table 4 shows that, given the small sample sizes, in patients with IBD and LNH, the occurrence of Bifidobacterium spp, $B$ adolescentis, B longum, E biforme, F prausnitzii, P productus, L acidophilus, Bacteroides fragilis group, $B$ distasonis, Clostridium coccoides group and $C$ clostridiiforme do not differ markedly compared with controls. Conversely, the detection rate of $B$ thetaiotaomicron seems to be lower in ileal mucosa of patients with Crohn's disease and was undetectable in the caecum and rectum mucosa of patients with indeterminate colitis. However, the pattern of incidence of $B$ vulgatus seems to be the most different, the occurrence of PCR positivity for this anaerobe being lower in patients with Crohn's disease and ulcerative colitis, as compared with controls, whereas all patients with indeterminate colitis were negative. The occurrence of both of these Bacteroides spp was almost never associated in each patient group studied. The detection rate of Prevotella spp in rectal biopsy specimens from patients with ulcerative colitis was higher than in controls.

\section{Quantitative analysis of bacterial DNA from Bacteroides vulgatus}

Real-time PCR was carried out for a quantitative analysis of Bacteroides vulgatus in ileum, caecum and rectum samples. The mean $C_{t}$ values were used to generate the reference curve for each predicted number of DNA copy of Bacteroides vulgatus ATCC 8482. The concentration range $0.05-50000 \mathrm{pg} /$ tube corresponded to $1 \times 10^{1}-1 \times 10^{7}$ cells/tube. In the reference curve, used to extrapolate the equivalent number of CFU of Bvulgatus in the biopsy specimens, $\mathrm{R}=0.999$ and the slope was -3.45 .

Figure 2 reports the results as the percentage of patients with different concentrations of Bacteroides vulgatus adherent to ileal mucosa calculated from cfu values $(0-100,100-1000$ and 1000-10 $000 \mathrm{cfu})$. Data obtained with the real-time PCR technique confirm a significant reduction $(p<0.05)$ of the percentage of samples positive for Bacteroides vulgatus in patients with IBD compared with controls. Up to $62.5 \%$ of controls and $42 \%$ of patients with LNH showed high concentrations of bacteria (1000-10000 and >10 $000 \mathrm{cfu}$ ), whereas lower concentrations $(0-100 \mathrm{cfu})$ were found in biopsy specimens of patients with IBD, reaching 67\% in patients with Crohn's disease, $57 \%$ in patients with ulcerative colitis and $75 \%$ in patients with indeterminate colitis. The trend in the quantitative analysis of Bacteroides vulgatus carried out in caecum and rectum biopsy specimens showed only slight variations in the number of cfu in comparison with that observed in ileum specimens (data not reported).

\section{DISCUSSION}

In humans, the composition of the flora is individual but stable, and differs between the stomach and upper bowel, lower small bowel, right colon and rectum. ${ }^{6}{ }^{13}$ Moreover, the flora recovered from faeces is also different from mucosaassociated or intraepithelial flora. ${ }^{6}{ }^{21}$ The resident microbiota has a critical role in modulating the immune response of the gut as well as in the initiation and perpetuation of IBD. In the normal host, the protective cell-mediated and humoral immune responses to enteropathogenic microorganisms are allowed to proceed, whereas responses to microorganisms of the indigenous flora are prevented. Differently, under conditions of chronic intestinal inflammation, this homeostasis seems to be disrupted, and the commensal flora seem to act as a surrogate bacterial pathogen: the lifelong inflammation in chronic IBD occurs because the host response in unable to eliminate the flora. ${ }^{31}$ Several lines of evidence in adults and in various animal models emphasise the role of the endogenous normal intestinal microflora in the aetiology of IBD. ${ }^{12} 1332$

This study represents the first report investigating the intestinal microflora in paediatric patients with IBD as well as in children with symptoms suggesting IBD but exhibiting a predominant pattern of ileal LNH. We chose to analyse the mucosa-associated microflora, as it is strictly joined to epithelial and immune cells and could have a central role in the pathogenesis of IBD. ${ }^{21}{ }^{29}$ Using a simple and reliable protocol of biopsy treatment, in which the overlying mucus layer was removed, we found a higher number of mucosaassociated facultative-anaerobic and aerobic bacteria in the ileum, caecum and rectum of children with IBD and INH than in controls, with the highest numbers found in patients with indeterminate colitis and Crohn's disease. However, in some instances, we found a great individual variability in the concentrations of mucosa-associated bacteria, in particular, Gram-positive bacteria, within the different groups of patients examined. As the age of our patients was far beyond the first 12 months, we could exclude any effect of age on the composition of the luminal microflora. Indeed, it is widely known that in the infant the establishment of the microflora is paralleled by maturing intestinal anatomy and physiology, with birth and weaning representing key stages at which bacteria colonise and species are established. ${ }^{5}$

Our findings are in agreement with those of other authors who showed that in adults, the mucosal surface of controls was essentially sterile and that the concentrations of mucosaassociated bacteria were increased in IBD, ${ }^{12} 21$ although some previous microbiological studies had reported no or little 
Table 4 Number of patients with positive polymerase chain reaction for anaerobic bacterial groups or species in biopsies from ileum, caecum and rectum

\begin{tabular}{|c|c|c|c|c|c|c|c|c|c|c|c|c|c|c|c|}
\hline & \multicolumn{3}{|c|}{ Controls } & \multicolumn{3}{|l|}{$C D$} & \multicolumn{3}{|c|}{ UC } & \multicolumn{3}{|l|}{ IC } & \multicolumn{3}{|c|}{ LNH } \\
\hline & $I$ & $\mathrm{C}$ & $\mathbf{R}$ & 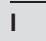 & $\mathrm{C}$ & $\mathbf{R}$ & $I$ & C & $\mathbf{R}$ & I & C & $\mathbf{R}$ & 1 & $\mathrm{C}$ & $\mathbf{R}$ \\
\hline Total patients (n) & 8 & 6 & 6 & 12 & 10 & 10 & 7 & 6 & 6 & 4 & 4 & 4 & 12 & 5 & 5 \\
\hline Bifidobacterium spp & 8 & 5 & 3 & 8 & 6 & 6 & 7 & 5 & 4 & 3 & 4 & 4 & 9 & 4 & 2 \\
\hline$B$ adolescentis & 2 & 0 & 0 & 3 & 3 & 3 & 1 & 0 & 0 & 0 & 0 & 0 & 0 & 0 & 0 \\
\hline$B$ longum & 3 & 2 & 2 & 3 & 3 & 3 & 2 & 1 & 1 & 1 & 0 & 0 & 3 & 2 & 2 \\
\hline Prevotella spp & 2 & 0 & 0 & 1 & 1 & 3 & 1 & 1 & 4 & 0 & 0 & 0 & 4 & 0 & 0 \\
\hline Clostridium coccoides group & 8 & 6 & 6 & 10 & 8 & 9 & 7 & 6 & 6 & 4 & 4 & 2 & 12 & 5 & 5 \\
\hline C clostriiforme & 7 & 4 & 4 & 7 & 6 & 6 & 6 & 5 & 4 & 3 & 2 & 2 & 11 & 4 & 3 \\
\hline Bacteroides fragilis group & 7 & 2 & 2 & 9 & 7 & 7 & 4 & 3 & 3 & 3 & 3 & 3 & 8 & 1 & 1 \\
\hline B thetaiotaomicron & 4 & 1 & 2 & 1 & 3 & 4 & 2 & 2 & 2 & 1 & 0 & 0 & 7 & 1 & 2 \\
\hline$B$ distasonis & 1 & 0 & 1 & 0 & 0 & 0 & 2 & 0 & 0 & 0 & 0 & 0 & 3 & 0 & 1 \\
\hline$B$ vulgatus & 7 & 6 & 6 & 3 & 3 & 3 & 3 & 2 & 2 & 0 & 0 & 0 & 12 & 5 & 5 \\
\hline E biforme & 0 & 0 & 0 & 1 & 0 & 0 & 0 & 0 & 0 & 0 & 0 & 0 & 1 & 0 & 0 \\
\hline F prausnitzii & 3 & 4 & 4 & 7 & 5 & 6 & 5 & 4 & 4 & 2 & 4 & 2 & 9 & 4 & 4 \\
\hline$P$ productus & 6 & 4 & 5 & 7 & 6 & 5 & 6 & $\begin{array}{l}4 \\
5\end{array}$ & 5 & 2 & 2 & 2 & 11 & 4 & 4 \\
\hline L acidophilus & 0 & 0 & 0 & 0 & 0 & 0 & 1 & 1 & 1 & 0 & 0 & 0 & 0 & 0 & 0 \\
\hline
\end{tabular}

C, caecum, CD, Crohn's disease; I, ileum, IC, indeterminate colitis; PCR, polymerase chain reaction; R, rectum; UC, ulcerative colitis.

Data are expressed as the number of patients with positive PCR for each target bacterium to the total number of patients in each group.

difference in bacterial concentrations between patients with IBD and controls. ${ }^{33-35}$ This discrepancy could be attributed to the different experimental conditions used in the studies, including transport and washing, handling conditions, biopsy sampling and detection procedures, as well as molecular probes used, and to the fact that location and grade of mucosa inflammation might also have influenced the bacterial concentration.

Data analysis of the different mucosa-associated bacterial species detected showed a generalised similar distribution of bacterial isolates among all patient groups, even though the highest heterogeneity of species was found in the ileal mucosa of patients with Crohn's disease. Interestingly, the detection of bacterial species among all patient groups showed that $E$ coli was isolated in patients with IBD and in controls, but its loading associated with intestinal mucosa in patients with IBD resulted in a noticeable increase (data not shown). As already postulated for some adherent-invasive $E$ coli strains, ${ }^{18-21}$ the role of Klebsiella spp in the pathogenesis of IBD and LNH disorders should be further investigated. Altered mucosal glycosylation in $\mathrm{IBD}^{36}$ could modify the interactions between the mucosa and microbial adhesins,

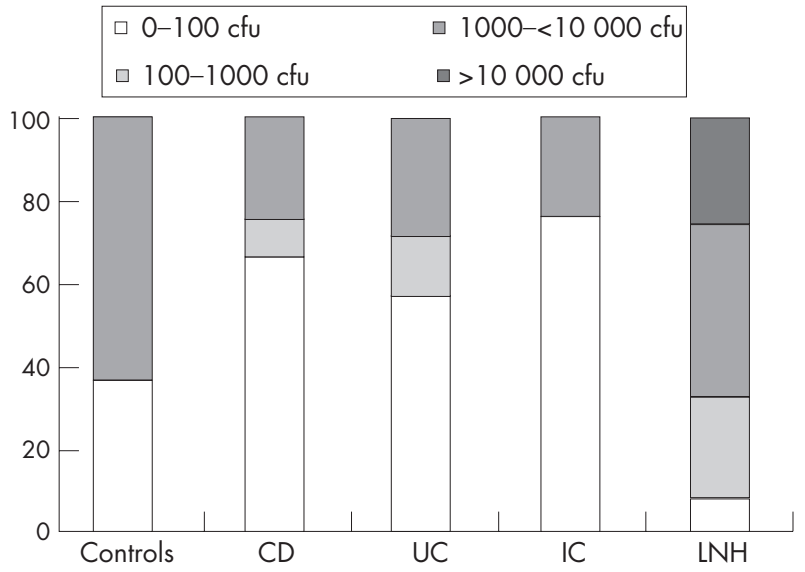

Figure 2 Percentage of patients with different concentrations of Bacteroides vulgatus adherent to ileal mucosa biopsy specimens. CD, Crohn's disease; cfu, colony forming units; IC, indeterminate colitis; LNH, lymphonodular hyperplasia; UC, ulcerative colitis. thus selecting particular bacterial strains from the commensal microbiota.

As in previous reports, ${ }^{37} 38$ we were unable to isolate pathogenic bacteria, such as Yersinia spp, Campylobacter spp or $L$ monocytogenes species and yeasts, supporting the finding that no specific pathogen is generally involved in IBD.

By using DNA-based molecular techniques, marked differences were seen in the occurrence of anaerobic species in ileum, caecum and rectum biopsy specimens from patients with IBD only; qualitative and quantitative detection of Bacteroides vulgatus showed a reduction of this microorganism in samples from patients with Crohn's disease and indeterminate colitis. An intriguing result was the marked increase in Prevotella spp only in the rectum of patients with ulcerative colitis, in accordance with the prevailing inflammatory involvement of the rectum in this disorder.

Although some cultures as well as culture-independent studies have shown a possible increase in Bacteroides spp in adult patients with Crohn's disease, ${ }^{12} 3940$ other reports have shown that IBD is associated with loss of some anaerobic bacteria related to the intestinal mucosa. ${ }^{13}{ }^{15} 41$ The lack of detection of Bacteroides vulgatus from all locations of the mucosa in patients with indeterminate colitis is in agreement with the experimental observations of Waidmann et al ${ }_{1}^{17}$ who suggested a protective role of this species against $E$ coliinduced colitis, supporting the importance of this bacterium in the "physiological inflammation". ${ }^{31}$ Our overall data analysis showed that in patients with indeterminate colitis, the total absence of Bacteroides vulgatus and Bacteroides thetaiotaomicron or their decrease in concentration were almost always coupled with the occurrence of Klebsiella spp. The low recovery of the Bacteroides group in patients with Crohn's disease and the associated-presence of $E$ coli strains may represent an interesting finding that should be further investigated. These findings strongly support the hypothesis that in patients with IBD a change in the microbial ecosystem, consisting of an altered colonisation of the gut mucosa by aerobic and anaerobic species, may occur.

The results of this study contribute to the understanding of modifications in the bacterial flora among patients with IBD and controls. Indeed, these data support the hypothesis that the global composition of the intestinal microflora rather than the presence of single pathogens can be relevant for the aetiology and pathogenesis of paediatric IBD. $^{41}$ It is 
conceivable that changes in the glycoprotein components of the intestinal mucosa, ${ }^{42-44}$ which characterise IBD, could determine loss or unmasking of receptors leading to a different selection of microorganisms present in the intestinal ecosystem. Hence, the decrease in Bacteroides vulgatus could be attributed to a lower association of this bacterium to gut mucosa, thus hindering its putative protective role, whereas the enhanced presence of $E$ coli in patients with IBD could be the result of the availability of new binding receptors. Moreover, knowledge of the distribution of microorganisms isolated from the gut of patients with IBD could be helpful not only to identify antibiotic targets, but also to obtain a therapeutic manipulation of the gut flora by probiotic or prebiotic strategies. However, this study is based on a small sample of patients and many comparisons, and thus significance tests, have been made. The statistical significance of these results should be viewed with caution. Some apparently significant results could be due to the large number of tests performed, whereas some statistically nonsignificant results may be due to the small sample sizes. Nevertheless, these results show that further studies are required to investigate the role of bacterial species found in paediatric patients with IBD, as well as putative differences in their virulence potential.

\section{Authors' affiliations}

M P Conte, S Schippa, I Zamboni, M Penta, F Chiarini, L Seganti, J Osborn, Department of Public Health Sciences, University of Rome, La Sapienza, University Hospital Umberto I, Rome, Italy

P Falconieri, O Borrelli, S Cucchiara, Department of Paediatrics, University of Rome, La Sapienza, University Hospital Umberto I, Rome, Italy

Funding: This work was supported by MIUR grants to MPC and SS.

Competing interests: None.

\section{REFERENCES}

1 Dunne C. Adaptation of bacteria to the intestinal niche: probiotics and gut disorders. Inflamm Bowel Dis 2001;7:136-45.

2 Hooper LV, Gordon Jl. Commensal host-bacterial relationships in the gut. Science 2001;292:1115-18

3 Shanahan F. The host-microbe interface within the gut. Best Pract Res Clin Gastroenterol 2002;16:915-31.

4 Holm H, Powrie F. Dendritic cells and intestinal bacterial flora: a role for localized mucosal immune response. J Clin Invest 2003;112:648-51.

5 Guarner F, Malagelada JR. Gut flora in health and disease. Lancet 2003;361:512-19.

6 Marteau P, Lepage P, Mangin I, et al. Gut flora and inflammatory bowel disease. Aliment Pharmacol Ther 2004;20:18-23.

7 Pirzer U, Schonhaar A, Fleischer B, et al. Reactivity of infiltrating T lymphocytes with microbial antigens in Crohn's disease. Lancet 1991;338:1238-9.

8 Macpherson A, Khoo UY, Forgacs I, et al. Mucosal antibodies in inflammatory bowel disease are directed against intestinal bacteria. Gut 1996;38:365-75.

9 Furrie E, Macfarlane S, Cummings JH, et al. Systemic antibodies towards mucosal bacteria in ulcerative colitis and Crohn's disease differentially activate the innate immune response. Gut 2004;53:91-8.

10 Hausmann M, Kiessling S, Mestermann S, et al. Toll-like receptors 2 and 4 are up-regulated during intestinal inflammation. Gastroenterology 2002; 122:1987-2000.

11 Hugot JP, Chamaillard M, Zouali $\mathrm{H}$, et al. Association of NOD2 leucine-rich repeat variants with susceptibility to Crohn's disease. Nature 2001;411:599-603.

12 Swidsinski A, Ladhoff A, Pernthaler A, et al. Mucosal flora in inflammatory bowel disease. Gastroenterology 2002;122:44-54.

13 Seksik P, Rigottier-Gois L, Gramet G, et al. Alterations of the dominant faecal bacterial groups in patients with Crohn's disease of the colon. Gut 2003;52:237-42

14 Schultsz C, Van Den Berg FM, Ten Kate FW, et al. The intestinal mucus layer from patients with inflammatory bowel disease harbours high numbers of bacteria compared with controls. Gastroenterology 1999;117:1089-97.

15 Kleessen B, Kroesen AJ, Buhr HJ, et al. Mucosal and invading bacteria in patients with inflammatory bowel disease compared with controls. Scand J Gastroenterol 2002;37:1034-41.
16 Rath HC, Wilson KH, Sartor RB. Differential induction of colitis and gastritis in HLA-B27 transgenic rats selectively colonized with Bacteroides vulgatus or Escherichia coli. Infect Immun 1999;67:2969-74.

17 Waidmann $M$, Bechtold O, Frick JS, et al. Bacteroides vulgatus protects against Escherichia coli-induced colitis in gnotobiotic interleukin-2 deficient mice. Gastroenterology 2003;125:162-77.

18 Darfeuille-Michaud A, Boudeau J, Bulois P, et al. High prevalence of adherent-invasive Escherichia coli associated with ileal mucosa in Crohn's disease. Gastroenterology 2004;127:412-21.

19 Boudeau J, Glasser AL, Masseret E, et al. Invasive ability of an Escherichia coli strain isolated from the ileal mucosa of a patient with Crohn's disease. Infect Immun 1999;67:4499-509.

20 Boudeau J, Barnich N, Darfeuille-Michaud A. Type 1 pili-mediated adherence of Escherichia coli strain LF82 isolated from Crohn's disease is involved in bacterial invasion of intestinal epithelial cells. Mol Microbiol 2001;39: 1272-84

21 Martin HM, Campbell BJ, Hart CA, et al. Enhanced Escherichia coli adherence and invasion in Crohn's disease and colon cancer. Gastroenterology 2004; 127:80-93

22 Tamboli CP, Neut C, Desreumaux P, et al. Dysbiosis in inflammatory bowel disease. Gut 2004:53:1-4.

23 Kokkonen J, Karttunen TJ. Lymphonodular hyperplasia on the mucosa of the lower gastrointestinal tract in children: an indication of enhanced immune response? J Pediatr Gastroenterol Nutr 2002;34:42-6.

24 Conti F, Borrelli O, Anania $\mathrm{C}$, et al. Chronic intestinal inflammation and seronegative spondyloarthropathy in children. Dig Liv Dis 2005;37:761-7.

25 Geboes K, De Hertogh G. Indeterminate colitis. Inflamm Bowel Dis 2003;9:324-31.

26 Wang RF, Cao WW, Cerniglia CE. PCR detection and quantitation of predominant anaerobic bacteria in human and animal fecal samples. Appl Environ Microbiol 1996;62:1242-7.

27 Matsuki T, Watanabe K, Fujimoto J, et al. Development of 16S rRNA-genetargeted group-specific primers for the detection and identification of predominant bacteria in human feces. Appl Environ Microbiol 2002;68:5445-51.

28 Drasar BS, Roberts AK. Control of the large bowel microflora. In: Hill MJ, Marsh PD, eds. Human microbial ecology. Boca Raton, FL: CRC Press, 1990:95-100.

29 Lepage $P$, Seksik $P$, Sutren $M$, et al. Biodiversity of the mucosa-associated microbiota is stable along the distal digestive tract in healthy individuals and patients with IBD. Inflamm Bowel Dis 2005; 11:473-80.

30 Moore WEC, Holdeman LV. Human fecal flora: the normal flora of 20 Japanese-Hawaiians. Appl Microbiol 1974;27:961-79.

31 Haller D, Jobin C. Interaction between resident luminal bacteria and the host: can a healthy relationship turn sour? J Pediatr Gastroenterol Nutr 2004;38:123-36.

32 Elson CO, Sartor RB, Tennyson GS, et al. Experimental models of inflammatory bowel disease. Gastroenterology 1995; 109:1344-67.

33 Hartley MG, Hudson MJ, Swarbrick ET, et al. The rectal mucosa-associated microflora in patients with ulcerative colitis. J Med Microbiol 1992;36:96-103.

34 Hudson MJ, Hill MJ, Elliott PR, et al. The microbial flora of the rectal mucosa and faeces of patients with Crohn's disease before and during antimicrobial chemotherapy. J Med Microbiol 1984; 18:335-45.

35 Poxton IR, Brown R, Sawyerr A, et al. Mucosa-associated bacterial flora of the human colon. J Med Microbiol 1997:46:85-91.

36 Campbell BJ, Yu LG, Rhodes JM. Altered glycosylation in inflammatory bowel disease: a possible role in cancer development. Glycoconj J 2001;18:851-8.

37 Van Kruiningen HJ. Lack of support for a common etiology in Johne's disease of animals and Crohn's disease in humans. Inflamm Bowel Dis 1999:5:183-91.

38 Chen W, Li D, Wilson I, et al. Detection of Chlamydia pneumoniae by polymerase chain reaction-enzyme immunoassay in intestinal mucosa biopsies from patients with inflammatory bowel disease and controls. J Gastroenterol Hepatol 2002;17:987-993.

39 Ruseler-van Embden JG, Both-Patoir HC. Anaerobic Gram-negative faecal flora in patients with Crohn's disease and healthy subjects. Antonie Van Leeuwenhoek 1983:49:125-32.

40 Giaffer MH, Holdsworth CD, Duerden BI. The assessment of faecal flora in patients with inflammatory bowel disease by a simplified bacteriological technique. Med Microbiol 1991;35:238-43.

41 Ott SJ, Musfeldt M, Wenderoth DF, et al. Reduction in diversity of the colonic mucosa associated bacterial microflora in patients with active inflammatory bowel disease. Gut 2004;53:685-93.

42 Jacobs LR, Huber PW. Regional distribution and alterations of lectin binding to colorectal mucin in mucosal biopsies from controls and subjects with inflammatory bowel diseases. J Clin Invest 1985:75:112-18.

43 Hoskins LC, Agustines M, McKee WB, et al. Mucin degradation in human colon ecosystems. Isolation and properties of fecal strains that degrade $A B H$ blood group antigens and oligosaccharides from mucin glycoproteins. J Clin Invest 1985:75:944-53.

44 Corfield AP, Wagner SA, Clamp GR, et al. Mucin degradation in the human colon: production, sialidase, sialate $\mathrm{O}$-acetylesterase, $\mathrm{N}$-acetylneuraminate lyase, arylesterase, and glycosulfatase activities by strains of fecal bacteria. Infect Immun 1998;60:3971-8. 